徐光启的天教补儒思想

\title{
XU GUANGQI'S THOUGHT ON SUPPLEMENTING CONFUCIANISM WITH CHRISTIANITY
}

\begin{abstract}
徐真瑛
Anna Seo

PhD Candidat, Peking University

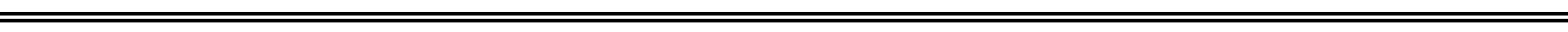

摘要

明末传教士来华之后, 在接受并推广基督教信仰的少数中国士大夫中, 徐光启是最具有影响力的人 之一。徐光启提出了天主教 “补儒易佛” 思想, 对以后基督教在中国的传播有深厚的影响。但是有的学 者认为他的思想不是纯粹的基督教思想, 而是儒家思想和天主教的一个大杂烩; 有的学者认为徐光启的 神学缺乏基督论; 还有的学者认为徐光启的天教补儒思想是以儒家为最高价值的, 他的最终目的是实现 儒家的政治理想。本文主要通过分析徐光启和传教士们的著作, 探讨徐光启对天主教的理解与实践, 来 考察他是如何将天主教与儒家思想结合起来的。本研究发现, 基督论是徐光启的天主观念的核心; 徐光 启对儒学的看法已经不完全是中国传统的看法, 而是通过天主教重新诠释的。在徐光启看来, 儒家的最 高价值就是敬畏上帝, 与天主教的最高价值一致。徐光启从事科学也是以归诚上帝为终极目的。徐光启 以天主教为框架, 系统地将天主教、儒家思想与科学结合起来, 建立了以敬畏天主为最高价值的天教补 儒思想。
\end{abstract}

关键词: 徐光启, 天主教, 儒家思想

\section{ABSTRACT}

$X u$ Guangqi is one of the most influential Chinese scholars who accepted Christian faith during the late Ming dynasty. His idea of "supplementing Confucianism and replacing Buddhism by Christianity" had great impact on the development of Christianity in China. His idea, however, has often been accused of syncretism, and genuineness of his Christian faith has been put into question. Some argue that his theology lacks Christology. Others suggest that his ultimate goal was to achieve the Confucian political ideals through adopting some of the Christian moral teachings. Through the analysis of Xu Guangqi' works and life, we find that he accepted all the essential Christian doctrines and Christology is the core of his understanding of "Tianzhu". His view on Confucianism itself is transformed through Christian perspective. In his new understanding, the ultimate goal of Confucianism is to serve and to worship "Tianzhu", same as Christianity. The ultimate problem of life is to save one's soul.Xu Guangqi considered his scientific works as a way to propagate Christian faith, since science was seen as an integral part of Christian thought and practice. His idea of "supplementing Confucianism by Christianity" integrated Confucianism into the overarching framework of Christian thought.

Keywords : Xu Guangqi, Christianity, Confucianism 


\section{内容}

明末传教士来华之后, 在接受并推广基督教信仰的少数中国士大夫中, 徐光启是最具有影 响力的人之一。徐光启提出了天主教 “补儒易佛” 思想, 对以后基督教在中国的传播有深厚的 影响。但是有的学者认为他的思想不是纯粹的基督教思想, 而是儒家思想和天主教的一个大杂 烩; 有的学者认为徐光启的神学缺乏基督论; 还有的学者认为徐光启的天教补儒思想是以儒家 为最高价值的，他的最终目的是实现儒家的政治理想。

本文主要通过分析徐光启和传教士们的著作, 探讨徐光启对天主教的理解与实践, 来考察 他是如何将天主教与儒家思想结合起来的。

本研究发现, 基督论是徐光启的天主观念的核心; 徐光启对儒学的看法已经不完全是中国 传统的看法, 而是通过天主教重新诠释的。在徐光启看来，儒家的最高价值就是敬畏上帝，与 天主教的最高价值一致。徐光启从事科学也是以归诚上帝为终极目的。徐光启以天主教为框架, 系统地将天主教、儒家思想与科学结合起来, 建立了以敬畏天主为最高价值的天教补儒思想。 关键词: 徐光启, 天主教, 儒家思想

徐光启 (1562-1633)，字子先，上海人。万历三十一年 (1603) 受洗成为天主教徒，时年四 十二岁, 圣名为保禄 (Paulus), 次年成进士, 累官至太子太保、礼部尚书兼文渊阁大学士, 谥文定。徐光启是中国历史上一位极为独特的思想家、科学家和政治家。明末传教士来华之后, 在真正地接受并且推广基督教信仰和西方科学理论的少数中国士大夫中, 徐光启是最具有影响 力的人物之一，被称为 “中西会通第一人”。

徐光启在利玛窦的天教合儒之说的基础上, 提出了以天主教 “补儒易佛” 的主张。徐光启 将从西方接受来的宗教信仰和科学知识, 与中国已有的思想传统结合起来, 并运用于修身、齐 家、治国等方面，成为一位具有开创性的儒家天主教徒。

但是关于徐光启的评价随着时代的演变在不断发生变化, 对他的 “天教补儒” 主张也有不 同的解释，甚至他的基督徒身份也从不同的角度被怀疑。《明史》本传 ${ }^{1}$ 、阮元的《畸人传》 ${ }^{2}$ 都 关注他在科学上的成就, 而完全忽略他的宗教思想和宗教活动。1906 年黄节撰写的《徐光启传》, 涉及到他的宗教活动，但他认为徐光启 “盖阳尊其教而阴取象数之学，以为己用”， “从事西 学, 思窥其象数之学以救汉宋以来空言论学之失” 3 。

法国著名汉学者谢和耐 (Jacques Gernet) 也怀疑徐光启信仰的纯粹性。谢和耐认为中西 方在思维方式、世界观、道德观、语言上存在着不可跨越的间隔, 中国人无法理解、接受三位 一体、道成肉身、耶稣受难等基督教的核心教义。 ${ }^{4}$ 尤其是中国人对基督受难的反应, 大部分 是无法理解, 完全排斥, 少数信徒也并没有接受基督论。他说: “十七世纪的中国基督徒, 在 他们的著作中从来没有提及耶稣, 而只是对上帝表示尊敬。” ${ }^{5}$ 所以中国信徒的信仰不是纯粹 的基督教信仰。徐光启的信仰也是儒家和基督教的一个大杂烩。

孙尚扬和钟鸣旦, 对此提出批评, 指出徐光启认为儒家思想有局限, 必需要天主教的补充; 并且他认为灵魂的拯救是人的终极问题。柯毅霖神父 (Fr. Criveller Gianni) 的《明末基督论》, 证明了徐光启接受了基督论。

许理和认为中国基督徒的著作以天主为中心，然而对耶稣人格即其与他有关的奥秘，特别 
是对天主降生成人却不甚在意, 他们的作品中缺乏基督论, 用 “天主主义” 这一词概括中国信 徒神学的特点。钟鸣旦反驳了这种错误观念。但是钟鸣旦和柯毅霖认为因为中国人更容易接受 天主观念, 而非基督观念, 并且由于用语的争论也集中在天主观念上, 因此信徒的作品中有关 天主的论题更多。

最近, 李春勇与陈卫平撰写的《徐光启评传》肯定徐光启的信仰是真诚的。但是, 还认为 徐光启 “没有放弃以儒学为最高价值的传统”。9 韩国学者金尚根 (Sangkeun Kim) 也主张徐 光启只是被西方科学和基督教的补儒易佛思想上的价值所吸引，他仍然是一位儒家。

本文主要通过探讨徐光启对天主教的理解与实践, 来更全面地考察他是否接受创造万物、 三位一体、道成肉身、受难救赎等核心教理。徐光启的神学是否缺乏基督论? 他是如何将天主 教与儒家思想结合起来的? 徐光启的最终目的是否是为了实现儒家的理想? 徐光启所持的 “补 儒易佛” 主张是否以儒家思想为最高价值, 在儒家的框架内接受天主教？他的思想是否是一个 “大杂烩” ?

\section{徐光启对基督教理的理解}

徐光启是否接受创造论、三位一体、道成肉身、耶稣受难等核心教义? 徐光启的神学是否 缺乏基督论？通过以下几方面，我们将对徐光启信仰的核心进行探讨。

第一, 徐光启在《景教堂碑记》云, “天地万物皆创矣” (页 531), 陈明他接受了天主创造 万物的教义。

第二, 徐光启第一次接触天主教, 就是通过耶稣基督像。徐光启在《跋〈二十五言〉》记载 自己入教的经历, 从瞻仰耶稣基督像说起: “昔游岑嵩, 则尝瞻仰天主像设, 盖从欧罗巴海舶 来也”（页 87）。“天主像设” 指的就是耶稣基督的像。徐光启通过耶稣像一开始接触 “道成 肉身”这一教理。

在徐光启看来中国人认识天主也就是通过耶稣基督像。这说明天主像对他的印象非常深刻。 在 1632 年写的《景教堂碑记》中, 徐光启说:

我中国之知有天主也，自利子玛窦之来宾始也。其以像设经典入献大廷，赐食大官，与 士大夫交酬问答，因而传播其书，兴起有众也。自万历庚子利子在入都门始也。其荘严 祠宇，崇奉圣像，使闻风企踵者瞻仰依归也，自万历辛亥利子之赐茥授室始也（页 531）。

第三, 据传教士柏应理 (Philippe Couplet, 1623-1693, 撰的《徐光启行略》和利玛窦的《利 玛窦中国传教史》对徐光启入教过程的叙述, 传教士给他讲解三位一体和道成肉身等一切核心 教义, 并且给他《天主实义》和《天主教要》等书, 徐光启读完后, 衷心悦服, 决心入教。《徐 光启行略》描述徐光启入教的过程:

庚子, 再入南都, 知利玛窦来自太西传天主正教, 因往候, 略闻其旨。归来得一梦, 见一圆堂 中, 设有三台: 一有像, 二无像, 既醒, 不识何解, 大以为异。癸印, 又至南都, 访利先生。 时利子已往都门, 明坚罗先生出接, 即引瞻拜天主像。罗子谓天主三位一体, 兹则第二位降生 为人之像。公忽忆前梦, 始惊疑, 以告罗子, 亦受天主默启, 因具讲圣教之理。公听之至暮无 倦志; 更访其旨, 罗子因以利子所译《实义》及《教要》诸书送阅。公持归邸舍, 彻夜不蒋, 
读之欣喜无已。遂曰: 我平生善疑, 至此而无可疑; 平生好辨, 至此而无可辨; 即立志愿受教。 待旦复入堂求教……

《天主实义》主要讲创造论, 但最后也讲天主降生、童女诞生、复活升天。《天主教要》 包括《天主经》、《天神朝拜圣母经》、《信经》、《十诫》、《四规》、《悔罪规文》等。 《天主经》是耶稣教弟子们的祷告文, 《天神朝拜圣母经》的内容是天神来告知圣母她将要通 过圣灵怀孕生子。《信经》的主要内容为三位一体和基督的降生受难复活升天:

我信全能者天主罷德勒, 化成天地。我信其惟一费略, 耶稣契利斯督, 我等主。我信其因 斯 彼利多三多, 降孕, 生於玛利亚之童身。我信其受难於般雀比刺多居官時, 被釬十字架, 死而 乃痊, 我信其降地獄, 第三日自死者中復生。我信其升天, 於全能者天主巴德勒之右坐。我信 其日后从彼而来审判生死者。我信 斯彼利多三多。我信有圣而公厄格勒西亚圣神相通功。我信 罪之赦。我信肉身之复生。我信常生。亚孟。

利玛窦（Matteo Ricci，1552-1610）的《中国传教史》也记载此事, 徐光启整夜研读《天 主教要》和《天主实义》, 并且《天主教要》里的祷告经文都背下来了 (卷下, 页 409)。徐 光启在《跋〈二十五言〉》说: “启生平善疑, 至是, 若披云然了无可疑; 时亦能作解, 至是, 若游溟然, 了亡可解; 乃始服膺请事焉” (页 87)。由此可知, 徐光启确实接触而接受了三位 一体、道成肉身的教理。

第四, 传教士们傅洗并不简单随意, 他们对愿意入教者总要进行严格的考核, 以确认他们 理解并相信天主教教义, 有意成为真正的基督徒。1605 年在至函罗马耶稣会士卢多维科 -马塞 利 (Ludouvico Mase11i) 神父的书信中利玛窦写道: “长期以来, 我恪守的宗旨就是宁缺勿滥。 我们对这些教友进行了十分严格的考核, 给他们打下了十分扎实的要理基础” ( 《利玛窦中国 书礼》，页 166）。

1608 年至耶稣会士吉罗拉莫 科斯塔（Girolamo Costa）神父的信中又写道: “目前的教 友已经有两千多人了。数量的确不多, 因为, 在这些大城市, 我们的宗旨是少而精。如果数量 很多，却并不符合基督信徒之名，宁可没有”（《利玛窦中国书礼》，页 169）。

第五, 在南京教难时, 反教人士猛烈攻击基督论, 徐光启明确表明自己相信其道理。南京 礼部拿获王丰肃等 13 名信徒后写的安民告示《拿获邪党后告示》列出天教之非，其中说：“乃 彼夷自刻《天主教解要略》, 明言天主生于汉哀帝某年, 其名曰耶稣, 其母亚利玛, 是西洋一 胡耳。又曰被恶官将十字枷钉死, 是胡之以罪死者耳。焉有罪胡而可名天主者乎? ” ${ }^{11}$ 徐光启 针对此写《辨学章疏》, 勇敢地承认自己就是基督徒, 并且帮助其传播: “臣尝与诸陪臣讲究 道理, 书多刊刻。则信向之者臣也。” 如果西士有罪, 他愿意与他们同受惩罚。 ${ }^{12}$ 他辩护天主 教说, “盖所言天主生育拯救之恩, 赏善罚恶之理, 明白真切”。 ${ }^{13}$ 其中 “拯救之恩” 指的是 耶稣基督为世人赎罪而拯救灵魂之恩惠。在他对天主教的理解中, 耶稣基督的拯救灵魂的恩惠 与创造万物、主宰赏罚一起具有核心地位。

第六, 徐光启表明他接受了传教士们所传的, 与中国传统里的上帝非常不一样的天主。传 教士龙华民反对利玛窦的合儒传教方法, 为了坚守天主教的纯粹性, 他强调中国的上帝和天主 教的天主的区别。他对中国基督徒进行了调查, 并在其中记载了与徐光启的对话: “(徐光启) 
认为上帝不可能是我们的天主, 古今文人均对天主一无所知。他相信古今中国人都不知道天主 是什么。但既然神父们出于善意称天主为上帝, 那么中士就不得反对。而且由于这个称号是相 称的, 他断定我们将归于天主的特性归于上帝是好的而且必要的。” ${ }^{14}$ 他所接受的天主是创造 万物的、降临到世界的、在十字架上死而复活的、拯救灵魂的、三位一体的，所以他说古今文 人对天主一无所知。他的意图也许在于表明自己信仰的纯粹性。他所说的天教补儒, 最大的一 点意义可能是对中国人天主观有补充。

最后, 在徐光启为艾儒略的《天主降生言行记略》写的《大讚诗》中描述了他信仰的核心。 柯毅霖指出, 此首诗证明徐光启 “清楚地把握了基督教的本质”。 ${ }^{15}$ 并且他用诗经的格式和语 言来赞扬天主, 准确, 典雅地陈述了基督教教义和基督徒的生活, 在形式和内容上, 非常好地 结合了天主教和儒家思想。《大赞诗》全文如下:

维皇大哉, 万汇原本; 巍巍尊高, 造厥胚浑。 抟捖众有，以资人灵；无然方命，忝尔所生。 蚌蚌黔首，云何不淑？曾是群信，上墋下黩。 帝曰悯斯, 降于人间; 津梁耳目, 㘫有三年。 普拯横流, 诞彰神奇; 舍尔灵躯, 请命作仪。 粤有圣宗, 十又二子; 述宣宏化, 以迨亿祀。 如日之升, 逾远而光。千六百载, 达于兹方。 兹方云何？膺受多祐。正教西来，大眷东顾。 凡我人斯，仰瞻辽廓。敢曰无主，敢曰不若? 大文无雕, 经涂无论。秉心三德, 守诫二五。 若周不升, 违周不坠。县矣前修, 无作后悔。 后悔则那，亟其改斿。鉴尔一息，芚尔百年。 如山罒嵬, 如海匪渊。矢志崇闪, 以隆德馨。

根据以上分析, 笔者认为, 徐光启的信仰与其说是天主教与儒家的大杂烩, 不如说更接近 纯粹的天主教的教理。

\section{天教补儒}

李春勇、陈卫平虽然肯定徐光启是虔诚的基督徒, 但是他们主张徐光启 “没有放弃以儒学 为最高价值的传统” , 他的最终目的是借助天主教伦理思想, 实现治国平天下的儒家理想。下 面, 我们将通过研究徐光启如何看待基督教思想和儒家思想的关系, 探讨 “天教补儒” 思想的 内涵。

第一, 应当指出, 徐光启对儒学的看法已经不完全是中国传统的看法, 而是通过天主教重 新诠释的。在徐光启看来, 儒家的最高价值就是敬畏上帝, 与天主教的最高价值一致。他在概 括天主教时，用儒家的词语说，“其说以昭事上帝为宗本”，“大者修身事天”，“其大者以归 诚上帝, 乾乾昭事为宗, 朝夕瞬息, 亡一念不在此” ${ }^{16}$, 他所说的上帝和天就是天主, 主张天 主教和儒家的终极目的, 最高价值是一致的。

第二, 徐光启所说的 “天教补儒” 与其说是以儒为最高体系的, 不如说是承认儒家思想的 不足, 以及强调以天教补充儒教的必要。徐光启认为儒家的理想通过儒家思想不能达到, 但是 如果奉行天主教, 儒家的理想也可以实现。 ${ }^{17}$ 徐光启在《辨学章疏》说: 
臣常论古来帝王之赏罚、圣贤之是非，皆范人于善、禁人于恶，至详极备。然赏罚是非， 能及人之外行, 不能及人之中情。又如司马迁所云: 颜因之夭, 盗跖之寿, 使人疑于善恶 之无报, 是以防范愈严, 欺计愈甚。一法立, 百弊生。空有愿治之心, 恨无必治之术…… 必欲使人尽为善, 则诸陪臣所传事天之学, 真可以补益王化, 左右儒术, 救正佛法者也。

虽然儒家思想极为重视道德伦理, 但儒家极为详细的规范也不能从根本上改变人的性情。徐光 启认为对天主的爱信与畏惧能够改变人的性情, 使人尽为善。他认为天主教的教理是 “天理人 情之至”，可以补充儒家思想的不足之处和其最终的困难。

徐光启强调天主教道德体系之所以切实可行是由于其对天主的信仰。他的道德伦理观是一 个整体的一部分, 与天主观互相有机结合, 不可分离。徐光启的叙述非常清楚地概括了天主教 与其伦理观的关系。“(天主教的）一切戒训规条，悉皆天理人情之至。其法能令人为善必真、 去恶必尽。盖所言天主生育拯救之恩, 赏善罚恶之理, 明白真切, 足以算动人心, 使其爱信畏 惧，发于由衷故也。”18

第三, 徐光启非常系统地区分大者与小者, 其终极目的与手段, 宗教、伦理与科学的关系, 并且非常清楚地表明他从事翻译科学、数学书的目的是为了传播天主教。他在《辨学章疏》说: “顾惟先生 (利玛实) 之学, 略有三种: 大者修身事天; 小者格物穷理; 物理之一端, 别 为象数”。一一皆精实典要, 洞无可疑。其分解擘析, 亦能使人无疑。而余乃亟傅其小者, 趋欲先其易信, 使人绎其文, 想见其意理, 而知先生之学可信不疑, 大概如是, 则是书 之为用更大矣。” 由此可知, 徐光启从事科学、数学的目的, 就是为了使人知道天主教可信无 疑。( 孙尚扬, 1994, 页 171)

然而, 谢和耐认为科学技术与天主教没有任何关系，徐光启的思想是儒家思想、科学与天主 教之间一个缺乏系统的结合。

这里不像传教士们想象和认为的那样, 指在纯世俗理论与宣扬超越一切真谛的宗教之间 进行角色的分配，而是指在儒教那不太明确的世俗和宗教体系与传教士们的伦理、宗教 和科学之间的结合。徐光启的这种看法不是也载于一部有关水法著作的序中了吗？而水 法则是一个没有任何基督教特征的学科。（Gernet，p．49）

事实上, 不同于谢和耐的观点, 在天主教看来世界都是在天主里统一的。耶稣会从建立伊 始, 就参与了各种各样的学术活动, 包括教学、研究和著述。“在所有事物上找到上帝” 是推 动他们研究的动机。在他们看来, 上帝创造了宇宙万物, 因而万物都隐藏着他的智慧、知识和 他对人的慈爱。科学研究是理解上帝, 与上帝沟通的一条路径。于是, 他们将研究领域从与教 会有关的学科 (像哲学和神学) 推广到所谓 “世俗” 或者 “日常” 的学科, 很多修道士在经院 里研究科学。他们研究的领域包括神学、论理、辨学、科学、技术、政治等, 这些形成了一个 完整的学术体系。与谢和耐的观念相反，天主教是一个包括世俗和科学的体系。

儒家思想也具有同样完整的体系, 包括形而上与形而下, 徐光启用儒家的术语概括西学为: “大者修身事天, 小者格物穷理”。徐光启在《几何原本杂议》说, 几何学的益处在于 “能令 学理者社其浮气, 练其精心”。在徐光启看来, 格物与修身有密切的关系, 儒家格物的目的是 修身治国平天下, 修身的终极目的是事天, 他们都把学问与道德相结合, 赋予科学研究以宗教 或者道德目的, 这是天主教与儒家思想的一个非常重要的共同点。儒家与天主教观念都不同与 谢和耐所代表的将宗教、世俗、伦理与科学等各个学问都分离的观点。从天主教与儒家思想的 角度看, 宗教、伦理与科学等学问互相不可分离。这就是天教补儒的一个非常重要的基础。 
第四, 徐光启在面对人生中最严肃的时刻, 仍能以天主教为最高价值为指导。徐光启认为 人的终极问题不是现世的治国平天下, 而是灵魂的拯救。据利玛窦《畸人十篇》, 利玛窦讲死后 的审判, 徐光启回应, “实人生最急事, 吾闻百惊怖其言焉”, “此皆忠厚语, 果大补于世教也。 今而后, 吾知所为备于死候。世俗之备于死也, 特求坚厚棺楟、卜吉宅兆耳, 孰论身后天台下 严审乎? ” (页 207，213) 由此可见徐光启确实相信死后天主审判, 认为备于死侯是 “人生最 急事”，这也解释了他为何劝家人与很多朋友入教。

方豪 (2007) 在《中国天主教人物传》说, “光启受洗后第一件事, 便是想邀请神父到上海 家乡开教, 并设法让全家人都信教” ${ }^{19}$ 。1606 年, 徐光启的父亲徐思诚 ${ }^{20}$ 与独子徐骥也受洗成为 天主教徒。他的妻子、岳父、孙子、孙女也都受洗了 ${ }^{21}$ 。1608 年, 徐光启请利玛窦派一名神父 到上海指导, 利玛窦就派了郭居静前往。在不到两年的时间里, 上海的天主教徒已经有二百多 人, 主要归功于徐光启的热情 ${ }^{22}$ 。根据徐宗泽的研究, 李天经 “与徐文定公善, 听其劝而入教” 。 金声也 “与徐光启善” 而 “领洗入教” ${ }^{23}$ 。

徐光启在他的岳父重病临死的时候写的一封家书中, 提到: “外公一病遂不起, 闻之伤悼痛 切。……所幸者已得进教, 又不幸先生不在, 临终不得与解罪, 不知汝曾令吴龙与一讲悔罪否? 此事甚急, 凡临终者即无先生在, 不可不自尽也。只要真悔, 无不蒙赦矣。” 24 方豪指出 “光 启对于其岳父临终时是否悔罪, 极为关心。” 25 可见徐光启的确相信拯救灵魂是 “人生最急事”, 也可以看出他在生活里活出了他的信仰。在他面对人生中最严肃的时刻, 仍能以天主教为最高 价值指导。因为他自己有了如此的信心，所以他确信事奉天主能够实现儒家不能达到的理想。 因为天主教包括关于永恒的信条，在永恒面前 “王化” 是短暂的目标。虽然徐光启肯定追求该 理想，但是在他眼里它不再是人生最急事，或者最大事。

徐光启在生活上体现以天主教为最高价值, 但仍然尽量采用儒家传统的天儒合一思想。我 们可从他筹办父亲丧礼一事中窥知一二。1607 年他的父亲去世, 在京丧葬。徐光启跟利玛窦商 议, 决定丧仪丧礼一切从礼, 免教外人疑信天主教徒轻薄先人, 礼仪则遵守教会典规, 兼采儒 家丧礼中不背教规者。利玛窦记述:

他对于父亲, 多尽孝思, 用不朽的木（楠木）作一棺，价值一百二十元宝（意大利银 币），适合自己的官身。但是他特加小心，绝不行一违反教规的礼仪; 事事都同神父们商 量。因此这次丧仪, 在京师里成了一件新奇事, 大家说是见所未见。……去世后几天我们 为他父亲举行隆重的追思礼, 在堂中设一奠状, 上盖黑线长幔, 周围安置蜡烛多支, 有设 香炉, 焚烧㭉乐博士 (徐光启) 的儿子所寄来的香料。葆乐博士亲自到堂, 身着丧服, 衣 粗麻衣, 戴白布巾, 腰系绳, 足踏素鞋, 式奇样特, 白色乃是这里的丧色。神父们唱弥撒, 葆乐博士和亲友等都满意这种丧仪。 ${ }^{26}$

丧礼的一切礼仪代表人们对生死的看法, 徐光启 “特加小心, 绝不行一违反教规的礼仪”, 即按照天主教的典规操办父亲的丧礼, 这表明他接受天主教的生死观, 并且对教外人表明自己 的信仰。丧礼是在儒家传统中最重要的礼仪之一，作为士大夫，按照天主教的礼仪举办父亲的 丧礼, 在当时来说是一件非常不简单的事。通过利玛窦的叙述可以看出, 徐光启与利玛窦十分 谨慎地对待这件事情, 在遵守天主教的教规的前提下, 也尽量采用儒家传统礼仪, 这无疑体现 了他们的天教补儒思想, 就是说以天主教为框架, 尽量采用儒家传统。

换句话，徐光启的思想和实践也可以用他概括天主教的几句话来代表：“其大者修身事天； 小者格物穷理; 物理之一端别为象数……” “其大者以归诚上帝, 乾乾昭事为宗。朝夕瞬息, 亡 一念不在此。” 27 


\section{结论}

根据以上分析, 可以总结以下的结论：徐光启系统地将天主教、儒家思想与科学结合起来, 建立了以天主为最高价值的天教补儒思想。他的天主观念是纯粹的基督教的观念。他提出天教 补儒, 认为通过天教对中国传统的上帝观、灵魂观与生死观的补充, 可以实现儒家的理想, 从 而可以用天主教作为框架结合儒家思想, 并在自己的生活中加以实践和运用。此外, 徐光启从 事科学也以归诚上帝为终极目的。可以说徐光启的思想不是儒家与天主教的大杂烩, 而是以天 主教为最高价值的儒家与天主教的有机结合。

\section{参考文献}

[比] 柏应理撰、张星曜编次: 《徐光启行略》, 徐宗泽编《徐文定公逝世三百年纪念文汇编》北京: 圣教 杂志社，1933 年。

[美]邓思：《从利玛窦到汤若望--晚明的耶稣会传教士》, 上海：上海古籍出版社， 2003 年。

方豪：《中国天主教史人物传》，北京：宗教文化出版社，2007 年。

黄节: 《徐光启传》, 《国粹学报史篇》1906 年 第十九期, 中国科学院中国自然科学史研究室编: 《徐光启 纪念文集--纪念徐光启诞生四百周年》, 北京: 中华书局, 1963 年。

[意]利玛窦《利玛窦中国书礼》宗教文化出版社，2006 年。

李春勇、陈卫平《徐光启评传》, 南京: 南京大学出版社 2006 年。

李之藻编辑：《天学初函》(共六册), 台湾: 台湾学生书局版, 1965 年。

罗光: 《徐光启传》, 台北: 传记文学出版社, 1981 年。

孙尚扬: 《利玛窦与徐光启》, 北京: 新华出版社, 1993 年。

孙尚扬: 《基督教与明末儒学》, 北京: 东方出版社, 1994 年。

孙尚扬, [比] 钟鸣旦：《1840 年前的中国基督教》, 学苑出版社, 2004 年。

王重民辑校：《徐光启集》，上海：上海古籍出版社，1984 年。

徐昌治: 《破邪集》, 载郑安德: 《明末清初耶稣会思想文献汇编》，第五卷，第 76 页。

徐宗泽：《中国天主教传教史概论》，上海，上海书店，1990 年。

钟鸣旦 (Nicolas Standaert)、杜鼎克 (Ad Dudink) 编: 《耶稣会罗马档案馆明清天主教文献》, 台北利氏 学社, 2002 年。

Criveller, Gianni, Preaching Christ in Late Ming China: The Jesuits' presentation of Christ from Matteo Ricci to Giulio Aleni, Taipei: Taipei Ricci Institute, 1997

Gernet, Jacques, trans. by Janer Lloyd, China and Christian Impact: A Conflict of Cultures, NY: Cambridge University Press. 1985.

Kim, Sangkeun, Strange names of God: the Missionary Translation of the Divine Name and the Chinese responses to Matteo Ricci's "Shangti" in late Ming China, 1583-1644, Peter Lang Publishing, 2004. 
1 《明史》卷二百五十一, 说 “从西洋人利玛窦学天文历算火器, 尽其术。” 徐光启著, 王重民编: 《徐 光启集》，上海：上海古籍出版社，1984 年，第 550 页。

2 载于《畴人传》第三十二卷。阮元评价徐光启说：“从西洋人利玛窦学天文推步，尽得其术，为译《 几何原本》、《测量法义》等书。……利氏东来, 得其天文数学之传者光启为最深”。徐光启著, 王重 民编：《徐光启集》，上海：上海古籍出版社，1984 年，第 580 页。

3 黄节: 《徐光启传》, 《国粹学报史篇》1906 年 第十九期, 中国科学院中国自然科学史研究室编: 《徐光 启纪念文集--纪念徐光启诞生四百周年》，北京：中华书局，1963 年。

4 Jacques Gernet, Chine et Christianisme, action et reaction. Paris, 1982. English version entitled China and the Christian Impact: A Conflict of Cultures, trans. By Janet Lloyd. Cambridge, England. 1985.

5 同上, p.223.

6 同上, p. 66 .

7 Criveller, Gianni, Preaching Christ in Late Ming China: The Jesuits' presentation of Christ from Matteo

Ricci to Giulio Aleni, Taipei: Taipei Ricci Institute, 1997 [意] 柯毅霖著, 王志成、思竹、汪建达译: 《晚 明基督论》，四川人民出版社，1999 年。

8 同上, 页 345

9 李春勇、陈卫平《徐光启评传》, 南京: 南京大学出版社 2006 年。第 173 页。

$10 \mathrm{Kim}$, Sangkeun, Strange names of God: the Missionary Translation of the Divine Name and the Chinese responses to Matteo Ricci's "Shangti" in late Ming China, 1583-1644, Peter Lang Publishing, 2004.p.225.

11 徐昌治: 《破邪集》, 载郑安德: 《明末清初耶稣会思想文献汇编》, 第五卷, 第 76 页。

12 徐光启: 《辨学章疏》, 王重民编《徐光启集》, 上海: 上海古籍出版社, 1984 年, 第 432 页。

13 同上，第 432 页。

${ }^{14}$ Longobardi, Responsio, 222, Sangkeun Kim, Strange Names of God, p. 222.

15 同上，页 335 .

16 徐光启: 《跋〈二十五言〉》，《徐光启集》，第 87 页。

17 孙尚扬指出, 这是对当时的儒家来说是 “令人惊奇的结论”。孙尚扬： 《基督教与明末儒学》, 北京: 东方出版社，1994 年，第 176 页。

18 徐光启: 《辨学章疏》, 《徐光启集》, 第 432 页。

19 方豪: 《中国天主教人物传》，北京：宗教文化出版社，2007 年，第 73 页。

20 徐光启说他父亲 “于阴阳医术星相占候二氏之书, 多所通综, 每为人陈说讲解, 亦娓娓终日。晚 年悉弃去，专意修身事天之学”。徐光启：《先考事略》，王重民：《徐光启集》，上海：上海古 籍出版社, 1984 年, 第 526 页。

21 徐光启的孙女徐甘第大 (Candida Xu) (1607-1680)也成为当时著名的基督徒, 帮助传教士建立许 多教会, 照顾乞正和被遗弃的女婴, 帮助在教难中遇难的传教士们。宋美龄的外祖母为徐光启第 九世女孙; 宋美龄说: “徐氏自徐光启以来, 教理为世代不易之信仰。” 徐家共出了徐允希、徐宗 泽、徐㻑禧、徐应桥、徐俊兴等十二位神父。现在台湾的徐俊兴神父是徐光启第十一代世孙。

22 [美] 邓思：《从利玛窦到汤若望--晚明的耶稣会传教士》，上海：上海古籍出版社，2003 年，第 84、97 页。

${ }^{23}$ 徐宗泽: 《中国天主教传教史概论》，上海，上海书店，1990 年，第 190、191 页。

${ }^{24}$ 徐光启: 《家书十一》, 《徐光启集》, 第 492 页。

25 方豪: 《中国天主教史人物传》，第 74 页。

${ }^{26}$ Fonti Ricciane. (D'Elia) Vol. II. p. 361. 罗光: 《徐光启传》, 第 47 页。

27 徐光启: 《跋〈二十五言〉》, 《徐光启集》, 第 87 页。 